\title{
Research on Influence Factors of Synergy of Enterprise Technological Innovation and Business Model Innovation in Strategic Emerging Industry
}

\author{
Hui Zhang \\ School of management, Hangzhou Dianzi University, Hangzhou, China \\ zhanghui816@126.com
}

\begin{abstract}
Keywords: Strategic emerging industry, Technological innovation, Business model innovation, Synergy.
\end{abstract}

\begin{abstract}
Developing strategic emerging industry has become an important measure to accelerate economic transformation and upgrading of one country and regions. The text constructs system frame of synergy of technological innovation and business model innovation in strategic emerging industry, and divides influence factors of synergy of the two innovations into four systems: strategic guidance, synergetic approach, institutional arrangement and organizational support. By the questionnaire investigation and factor analysis, the text classifies the four systems into six factors: executive's synergy capability, synergetic strategic orientation, synergetic innovation culture, synergetic information communication, synergetic incentive mechanism and synergetic organizational structure. Finally, the text puts forward management structure of synergetic innovation of technological innovation and business model innovation on the basis of the six factors.
\end{abstract}

\section{Introduction}

Strategic emerging industry is a strategic and future directional industry in China's hi-tech industries, and creating its effective industries development model is considered as a deep-level study that need solve urgently at present China's socio-economic development. With the rapid development of science and technology and the high speed of scientific achievements' transformation, developing strategic emerging industry has become an important measure to accelerate economic transformation and upgrading of one country and regions and enhance the core competitiveness of the region. How to effectively lead into emerging industry and how to promote the development of emerging industry have become an important issue of all circles concern, and attracted widespread attention in theory and practice. There is close relationship between strategic emerging industry and technological innovation. Technological innovation is an accompanying phenomenon of enterprise competition in the market economy, and is a breakthrough of economic development to balanced pattern. Once this breakthrough involves fundamental technological innovation, especially when competition among developing countries evolves to take advantage of technological innovation to win international market share and position, the industrial innovation that is evolved by this technological innovation has strategic, and the formed industry is strategic emerging industry. Therefore, strategic emerging industry can be looked as a kind of laboratory economy. This laboratory is a kind of research and development institution by an entrepreneurial way to operate, and strategic emerging industry is the combination of technology breakthroughs of laboratory and marketization of innovative products. For the enterprise, technological innovation is to translate science and technology into productivity so as to create more competitive products. The business model is to create and deliver customer value and value system of the company. Through constant innovation, the firm can achieve value when firm creates value for others. Technology determines the output of products, and business model determines the sale of products. Technological innovation and business model innovation of firm interact, interactively and dynamically evolve, and together affect the development of firm. So how promotes synergy of technological innovation and business model innovation? Based on the existing literatures, this text analyzes the characteristics of technological innovation and business model innovation, and develops a construct of synergetic innovation between technology and business model innovation. Then, through the preliminary summary and classification of the influence factors, the text designs investigation questionnaires of influence factors, and confirms key factors gather of synergetic 
innovation of technology and business model innovation by factor analysis. Finally, the text puts forward some advices on realization of synergetic innovation management between technological innovation and business model innovation according to the key factors gather.

\section{Influence Factors of Business Model Innovation}

From the domestic and foreign literatures, we can see that it has mainly four views about power and influence factors of business model innovation: (1) View of technology promotion. Timmers (1998) and Amit and Zott (2001) thought, new technologies that were represented by internet technology were the main motive force of business model innovation [1,2]. Subsequently, The research of Kodama (2004), Faber etc (2003) and Yovanof and Hazapis (2008) also showed that, in the more extensive IT and ICT field, the technical changes of industrial modularization and industry integration etc promoted business model innovation of related companies in the American, European and Japan, and business model innovation helped enterprises to gain profit to a greater extent which technology changes brought $[3,4,5]$. (2)View of demand pulling. Deloitte Research (2002) found by the study of business model innovation of 15 companies that, the main driving force of promoting business model innovation was not technology, laws and regulations and social and economic changes, but the customer demand which enterprise made great efforts to satisfy the consumers [6]. (3)View of competition forced. IBM (2006) found by a survey for 765 CEOs and company senior executives in the world, approximately $40 \%$ CEOs and company senior executives worried about that business model innovation of competitors was likely to change fundamentally the prospect of the industry, therefore, they wanted their companies to participate in and control the business model innovation [7]. Venkatraman and Henderson (2008) studied the effect way of the pressure on business model innovation, and they found that changes in technology and management would bring pressure to the enterprises, when the pressure accumulated to a certain degree (or reached a critical point), the enterprise would produce the need of business model innovation [8]. (4)View of enterprise executives. The study of Linder and Cantrell (2000) showed by the interview of 70 executives and secondary data collection, enterprise executives were the main driving force to promote business model innovation; the 70 surveyed executives put their $30 \%$ innovation effort on business model innovation, and some executives even put business model innovation ahead traditional innovation [9]. The first three views are from the external perspective of firm to discuss influence factors of business model innovation, and only enterprise executive's view is from the internal perspective of firm to discuss influence factors of business model innovation.

\section{Influence Factors of Technological Innovation}

Many scholars found, the success of technological innovation was the joint result of many factors, and could not use simple and single factor to explain. The success of innovation meant that multiple functional departments could be qualified for the work and the innovation success was the result of their balance and coordination, and not just one or two things were super and excellence (Cooper and Schmidt, 1987). Song and Parry (1996) found by follow-up study of Japanese 788 new product development enterprises in four years, the success of new product development of Japanese enterprises was positive related to valid integration of $\mathrm{R} \& \mathrm{D}$, manufacturing and marketing, information sharing, marketing and technical resources of firm, technology capability, efficiency and experience of new product development, and market environment etc [10]. Rothwell (1992) respectively summarized nine and five success factors of innovation from the project level and firm level, and involved market orientation and satisfying user need, highly-efficient technology development, senior leadership attention, culture of encouraging innovation, communication among projects and organizational flexibility etc [11]. The study of Gang Zheng (2003) found that, the top ten key elements that impacted technological innovation performance of firm were successively: accurate grasp of market and user needs, corporate culture of encouraging innovation and tolerating failure, coordination of technological innovation strategy and business strategy, leadership attention degree, institution arrangement of innovation incentive, high quality R\&D personnel and training, enough innovative money and resources, information communication and knowledge management and R\&D capability and efficiency[12]. The research about the influence factors of technological 
innovation can be divided into the following two categories: internal motivation of firm and external motivation of firm. Internal motivation includes entrepreneurship, innovation culture, technical innovation ability, firm strategy, institution and organization etc; external motivation includes technology development force, market competition, induction and traction of government and demand pulling etc. This text is the research of synergy of technological innovation and business model innovation, so the text discusses influence factors of the two innovation synergy from internal and controllable view of firm, and hopes to put forward managerial advice for firm.

\section{Influence Factors of Synergy of Technological Innovation and Business Model Innovation}

Guang Chen (2001) studied main influence factors of synergetic innovation process and performance, and listed twenty factors and behavior description that might affect the synergy of innovation elements. He used the main factors analysis method of SPSS statistical software, and obtained the factors and sorted as follows in accordance with the priorities that affected innovation synergy: information communication, strategic culture, personnel relationship and organization structure [13]. Fang-rui Wang (2003) found that the influence factors of synergetic innovation of technological innovation and business model innovation could be divided basically into four levels: firm level, function level (department level), team level and individual level, and the factors of the four aspects showed the characteristics of three aspects: strategy, organizational structure and process and collaborative tools and the mechanism [14]. Xie Fang's study found the six key factors that effected internal synergetic innovation of enterprise group: collaborative atmosphere factor, incentive mechanism factor, organizational structure factor, lateral interaction factor, strategic factor and information bridge factor [15]. From the present researches, we can find that information transmission and communication is the prerequisite of synergetic innovation, and strategy, organization and institution (structure) restrict and affect synergetic innovation of enterprises. Therefore, according to the related research of influence factors of business model innovation and technological innovation and the characteristic of strategic emerging industry, this text argues that the synergy of technological innovation and business model innovation in strategic emerging industry need firm's support of four major systems: strategic guidance, synergetic approach, institutional arrangement and organizational support, and interconnect among various elements, interface and overall. With reference to measurement methods of above scholars, the measurement scale of the text is shown in table 1. The measurement scale stresses the importance of market and user needs, which is important for technological innovation and business model innovation.

\section{Factor Analysis of Influence Factors of Synergy}

This research mainly adopts questionnaire to collect sample data. The geographical scope of data collection is strategic emerging industry in Zhejiang province. The questionnaires were mailed to executives in 130 firms. Survey responses from 115 firms were received in time, of which 17 questionnaires were invalid, and 98 questionnaires were sufficiently complete. Thus, the overall firm-level effective response rate was $85.2 \%$. The questionnaire items were measured using a seven point scale anchored by ' $1=$ not at all' and ' $7=$ to a very great extent'. The measurement items are reported in the Table1. Table 1 is factor analysis by SPSS and shows the rotated principal components solution. KMO coefficient is 0.820 , and significant coefficient of Barteltt is 0.000.Twenty-four items have significant factor loadings $(\geq \pm 0.50)$ on one of the six factors. The Cronbach's $\alpha$ value of the scale of six factors is greater than 0.7 , so it shows that the scale has good reliability and validity. According to the related literature, we respectively name the six factors as follow: executive's synergy capability, synergetic strategic orientation, synergetic innovation culture, synergetic information communication, synergetic incentive mechanism and synergetic organizational structure. As was mentioned above, the influence factors of synergy of technological innovation and business model innovation include four systems: strategic guidance, synergetic approach, institutional arrangement and organizational support. The main role of strategic guidance system is to lead establishment of synergetic innovation base and the formation of synergetic behavior, and the system of strategic guidance includes executive's synergy capability factor and synergetic strategic orientation factor; the main role of organizational structure system is to 
establish the basis of synergetic innovation and provide the support of organizational structure of synergetic innovation, and organizational structure system includes synergetic organizational structure factor; the main role of synergetic approach is to promote the production of synergetic innovation behavior, and the system of synergetic approach includes synergetic information communication factor and synergetic incentive mechanism factor; the main role of institutional arrangement system is to form synergetic atmosphere by making some policy, and the system of institutional arrangement includes synergetic innovation culture factor.

Tab. 1 Factor Analysis

\begin{tabular}{|c|c|c|c|c|c|c|}
\hline Items & F1 & F2 & F3 & F4 & F5 & F6 \\
\hline $\begin{array}{l}\text { F1: synergetic strategic orientation } \alpha=.871 \\
\text { Overall strategy of firm pays attention to technological } \\
\text { innovation and business model innovation. }\end{array}$ & .633 & .278 & .111 & .063 & .306 & 285 \\
\hline $\begin{array}{l}\text { Firm pays attention to strategic match of technological } \\
\text { innovation and business model innovation. }\end{array}$ & .799 & .212 & .073 & .113 & .125 & .148 \\
\hline $\begin{array}{l}\text { Corporate vision embodies the combination of profit, } \\
\text { customer demand and technical ability. }\end{array}$ & .735 & .234 & -.132 & .014 & .233 & .079 \\
\hline $\begin{array}{l}\text { Strategic planning encourages resource integration of } \\
\text { technology, management and market etc. }\end{array}$ & .726 & .123 & .137 & .051 & .189 & .209 \\
\hline $\begin{array}{l}\text { Enterprise strategic pays attention to accurate grasp of market } \\
\text { and user needs. }\end{array}$ & .785 & .092 & .069 & .026 & .113 & .222 \\
\hline $\begin{array}{l}\text { F2: executive's synergy capability } \alpha=.831 \\
\text { Leaders attach great importance to synergetic innovation. }\end{array}$ & .103 & .696 & .104 & -.078 & .154 & .221 \\
\hline Executives can capture and seize market opportunities in time. & .212 & .855 & .067 & .124 & .009 & .073 \\
\hline $\begin{array}{l}\text { Executives can integrate and allocate resources to match } \\
\text { company's strategy. }\end{array}$ & .269 & .661 & .151 & .122 & .229 & .158 \\
\hline $\begin{array}{l}\text { Executives have strong innovation ability and are willing to } \\
\text { bear the risk and uncertainty. }\end{array}$ & .176 & .787 & -.112 & -.060 & .242 & .158 \\
\hline $\begin{array}{l}\text { F3: synergetic innovation culture } \alpha=.718 \\
\text { Innovation is the main theme of company development. }\end{array}$ & -.046 & .048 & .671 & -.066 & .277 & .075 \\
\hline $\begin{array}{l}\text { Firm encourages communication and cooperation among } \\
\text { employees. }\end{array}$ & .220 & -.064 & .724 & -.017 & .000 & .162 \\
\hline Firm encourages employees to innovation. & .149 & .187 & .783 & -.245 & -.078 & .028 \\
\hline Firm encourages cooperative innovation of cross department. & -.149 & .064 & .600 & -.306 & .238 & -.041 \\
\hline $\begin{array}{l}\text { F4: synergetic information communication } \alpha=.891 \\
\text { Technology department and market department share } \\
\text { information and resource. }\end{array}$ & -.026 & .064 & -.120 & .847 & -.040 & .124 \\
\hline $\begin{array}{l}\text { Technology department and market department have formal } \\
\text { information communication mechanism. }\end{array}$ & .147 & .079 & -.131 & .862 & .098 & -.039 \\
\hline $\begin{array}{l}\text { Informal communication between market and technology } \\
\text { personnel has guarantee measures. }\end{array}$ & .118 & -.050 & -.054 & $\mathbf{. 8 2 8}$ & .187 & -.057 \\
\hline $\begin{array}{l}\text { The utilization rate of information communication technology } \\
\text { between different departments is very high }\end{array}$ & -.026 & .012 & -.156 & .869 & .099 & .037 \\
\hline $\begin{array}{l}\text { F5: synergetic organization structure } \alpha=.788 \\
\text { Organization structure form pays attention to departments' } \\
\text { connection. }\end{array}$ & .280 & .168 & .105 & .151 & .691 & .174 \\
\hline Organizational structure is very flexible. & 207 & .066 & .020 & .080 & .770 & .222 \\
\hline $\begin{array}{l}\text { Firm pays attention to building of project team of cross } \\
\text { function. }\end{array}$ & 298 & .352 & .216 & .077 & .645 & -.003 \\
\hline $\begin{array}{l}\text { Firm encourages reasonable job rotation between market and } \\
\text { technology personnel }\end{array}$ & .181 & .292 & .219 & .159 & .525 & .193 \\
\hline $\begin{array}{l}\text { F6: synergetic incentive mechanism } \boldsymbol{\alpha = . 8 5 1} \\
\text { Firm constructs salary system of encouraging synergy of } \\
\text { technological innovation and business model innovation }\end{array}$ & .278 & 239 & .051 & .016 & .249 & .755 \\
\hline $\begin{array}{l}\text { Firm has incentive mechanism to encourage personnel } \\
\text { cooperation of technology and market department. }\end{array}$ & .188 & .250 & .057 & .003 & .134 & .836 \\
\hline $\begin{array}{l}\text { Firm has incentive mechanism to encourage cooperation } \\
\text { innovation of cross sector. }\end{array}$ & .362 & .111 & .163 & .051 & .142 & .736 \\
\hline
\end{tabular}




\section{Conclusion and Management Advice}

The goal of synergetic innovation management of technological innovation and business model innovation points to system elements of synergetic innovation, such as conducting management of technology and market department as well as the link between the two. But the media of synergetic innovation management is various influence factors of synergetic innovation of technological innovation and business model innovation. Only when various influence factors are conducive to implement of synergetic innovation, firms can achieve the objective of synergetic innovation management. Under the orderly management of influence factors of synergetic innovation, the ordered state of self-organization process among the elements of system will come very naturally to achieve. Therefore, synergetic innovation management is not to manage synergy or synergy process, but manage the influence factors of synergetic innovation. Therefore, according to the characteristic of strategic emerging industry, technological innovation and business model innovation, this text divided influence factors of synergy of technological innovation and business model innovation in strategic emerging industry into four systems: strategic guidance, synergetic approach, institutional arrangement and organizational support. By the questionnaire investigation and factor analysis, the text classifies the four systems into six factors: executive's synergy capability, synergetic strategic orientation, synergetic innovation culture, synergetic information communication, synergetic incentive mechanism and synergetic organizational structure. Firm can base on the six factors and establish management structure of synergetic innovation of technological innovation and business model innovation. First, executive's synergy capability factor and synergetic strategic orientation factor play a guiding function for synergetic innovation under the support of synergetic innovation culture factor and synergetic organization structure factor, so that which can make the establishment of organization background of synergetic innovation and execution of synergy behavior have clear strategic development direction. Secondly, under the guidance of executive's synergy capability factor and synergetic strategic orientation factor, synergetic innovation culture factor and synergetic organization structure factor establish organizational base of implement of synergetic innovation behavior within the scope of the whole organization; Finally, under the guidance and support of executive's synergy capability factor, synergetic strategic orientation factor, synergetic innovation culture factor and synergetic organization structure factor, synergetic information communication factor and synergetic incentive mechanism factor specifically implement the task of synergetic innovation, and establish and develop combination system of synergetic innovation behavior in internal organization. Obviously, enterprises want to establish synergetic innovation system between technological innovation and business model innovation, from the guidance of synergetic innovation, establish of synergetic innovation base to task implement of synergetic innovation, every link is very important, and the lack of any one, synergetic innovation system of enterprises cannot effectively work. To build synergetic innovation system, it is essential that firm need comprehensively consider the main effect factors of synergetic innovation function. Only when firm establishes factor relation system on the basis of comprehensive influence factor analysis, it can effectively support the implement of collaborative innovation system. To sum up, if firm wants to carry on effective synergetic innovation management, firm must make synergetic innovation function as the master line, base on factor system connection, and establish comprehensive and systemic management architecture.

\section{Acknowledgement}

This research was supported by project of National Natural Science Fund (71302149), soft science project of Science Technology Department of Zhejiang Province (2013C35038) and project of Key Research Base of Philosophy and Social Science of Zhejiang Province (13JDJS02Z).

\section{References}

[1] Timmers P. Business models for electronic markets [J]. Electronic markets, 1998, 8(2): 3-8. 
[2] Amit R, Zott C. Value creation in e-business [J]. Strategic management journal, 2001, 22(6-7): 493-520.

[3] Kodama F. Measuring emerging categories of innovation: Modularity and business model [J]. Technological Forecasting and Social Change, 2004, 71(6): 623-633.

[4] Faber E, Ballon $\mathrm{P}$, Bouwman $\mathrm{H}$, et al. Designing business models for mobile ICT services[C]//Workshop on concepts, metrics \& visualization, at the 16th Bled Electronic Commerce Conference eTransformation, Bled, Slovenia. 2003.

[5] Yovanof G S, Hazapis G N. Disruptive technologies, services, or business models? [J]. Wireless Personal Communications, 2008, 45(4): 569-583.

[6] Deloitte Research. Deconstructing the formula for business model innovation [EB/OL]. http://doc.mbalib.com/view/7542ea61cf6e630a2c363e78cd1d9f4f.html, pdf, 2003.

[7] IBM Global Services. Business model innovation-the new route to competitive advantage [EB/OL]. http://www.docin.com/p-387988250.html.PDF.2006.

[8] Venkatraman N, Henderson J C. Four vectors of business model innovation: Value capture in a network era $[\mathrm{M}] / /$ From strategy to execution. Springer Berlin Heidelberg, 2008: 259-280.

[9] Linder J. Changing business models: surveying the landscape [M]. Accenture Institute for Strategic Change. 2000.

[10] Song X M, Souder W E, Dyer B. A causal model of the impact of skills, synergy, and design sensitivity on new product performance [J]. Journal of Product Innovation Management, 1997, 14(2): 88-101.

[11] Rothwell R. Towards the fifth-generation innovation process [J]. International marketing review, 1994, 11(1): 7-31.

[12] Gang Zheng. Research of comprehensively synergistic mechanism of all elements in the process of enterprise technology innovation based on the perspective of TIM [D]. Doctoral dissertation, Zhejiang University, 2003.

[13] Guang Chen. Synergy innovation theory and empirical study in enterprise [D]. Doctoral dissertation, Southwest Jiaotong University, 2005.

[14] Fang-rui Wang. Research of synergistic innovation management of enterprise technology innovation and market innovation based on total innovation management [D]. Master dissertation, Zhejiang University, 2003.

[15] Fang Xie. Research of synergetic innovation in enterprise group[D]. Master dissertation, Zhejiang University, 2003. 